\title{
Traumatic Acute Subdural Hematomas: Analysis of Outcomes and Predictive Factors at a Single Center
}

\author{
${ }^{1}$ Ankara Numune Education and Research Hospital, Department of Neurosurgery, Ankara, Turkey \\ ${ }^{2}$ Kutahya Evliya Celebi Education and Research Hospital, Department of Neurosurgery, Kutahya, Turkey \\ ${ }^{3}$ Deva Private Hospital, Department of Neurosurgery, Gaziantep, Turkey \\ ${ }^{4}$ Ankara Education and Research Hospital, Department of Neurosurgery, Ankara, Turkey \\ ${ }^{5}$ Ankara Numune Education and Research Hospital, Department of Emergency, Ankara, Turkey \\ ${ }^{6}$ Sincan State Hospital, Department of Neurosurgery, Ankara, Turkey \\ ${ }^{7}$ Memorial Private Hospital, Department of Neurosurgery, Ankara, Turkey
}

Fatih ALAGOZ1 ${ }^{1}$, Ali Erdem YILDIRIM¹, Mert SAHINOGLU1', Murat KORKMAZ², Mehmet SECER ${ }^{3}$, Haydar CELIK ${ }^{4}$, Cihat YEL ${ }^{5}$, Yahya GUVENC ${ }^{6}$, Ozhan Merzuk UCKUN ${ }^{1}$, Firat NARIN ${ }^{7}$ Ergun DAGLIOGLU1 ${ }^{1}$ Ahmet Deniz BELEN ${ }^{1}$

\section{ABSTRACT}

AIM: In the present study, we evaluated the association of the Glasgow Coma Scale (GCS) score and amount of blood loss with mortality in patients presenting with traumatic acute subdural hematoma (ASDH).

MATERIAL and METHODS: This retrospective study was performed on 99 patients who were operated for traumatic acute subdural hematoma (ASDH) without any systemic association at a single center. Epidural hematoma was reported to be the most common additional pathology. Age, sex, mechanism of trauma, time interval between onset of trauma and admission to the emergency ward, associated problems, thickness of hematoma and Glasgow Coma Scale (GCS) score at the time of admission and on discharge were all studied.

RESULTS: The GCS score was inversely proportional to the thickness of hematoma and interval between onset of trauma and surgery $(p<0.05)$. Although the mortality rate was reported to be high in traffic accidents, the rate was low in patients with head trauma only $(p<0.05)$. The mortality rate was high in patients with associated pathologies $(p<0.05)$. Lost patients were reported to be older patients with more extensive ASDH or those who presented earlier with a low $G C S(p<0.05)$.

CONCLUSION: ASDH is associated with high mortality. GCS score and the thickness of the ASDH are important predictors of mortality. Age, additional trauma, and interval between trauma and hospital admission are major predictive factors for mortality.

KEYWORDS: Acute subdural hematoma, Traumatic, Outcome, Predictive factors

\section{INTRODUCTION}

A cute subdural hematoma (ASDH) is a clinical entity with increased morbidity and mortality despite the developments in neurosurgery and urgent intervention is obviously necessary for an optimum clinical outcome $(5,24)$. Its mortality rate has begun to decline with the developments in medicine and is currently around 14\% (16).
ASDH might be classified into traumatic or non-traumatic and acute or chronic. It usually develops as a result of rupture of the bridging veins between the dura and cerebral cortex (17). It might also be associated with rupture of dural sinuses or superior cortical arteries. Traumatic ASDH is encountered in one third of severe head traumas and the mortality rate increases up to as high as $60 \%$ (2). Traumatic ASDH is seen usually in younger individuals compared to the non-traumatic variety 
but the incidence of ASDH goes up with simple head trauma in the elderly group $(2,4)$.

In the present study, we evaluated the influence of the Glasgow Coma Scale (GCS) score and thickness of hematoma factors on the mortality of traumatic ASDH.

\section{MATERIAL and METHODS}

This retrospective study was performed on 99 patients who were operated with the diagnosis of traumatic ASDH at the Neurosurgery Clinic of Ankara Numune Education and Research Hospital between January 2010 and December 2013. Age, sex, mechanism of trauma, time delay between the onset of trauma and admission, additional pathologies, thickness of hematoma and GCS score at admission and discharge were investigated. We focused on isolated head trauma describing patients without any systemic injury (e.g. abdominal, thorax or spinal cord injury that might affect prognosis of traumatic subdural hematoma). Factors that affected the mortality rate, GCS score and the size of ASDH were analyzed. Patients with lesions such as spontaneous acute subdural hematoma due to anticoagulant use (non-traumatic $A S D H$ ) were excluded from the study.

Data were collected from previously prepared patient information sheaths. Statistical analyses were performed using the SPSS (Statistical Package for Social Sciences) Windows 19 software package. Distribution of the variables was tested by the Kolmogorov-Smirnov test. The differences between groups' mean values were tested with Student's t-test. The significance of the differences with respect to the median values was evaluated using the Mann-Whitney $U$ test. The changes in the study variables in time were analyzed using the Wilcoxon test. A $p$ value less than 0.05 was considered statistically significant.

\section{RESULTS}

Ninety-nine patients were operated for traumatic ASDH at Neurosurgery Clinics of Ankara Numune Education and Research Hospital with a mean age of $46.8 \pm 21.3$ years (ranged between 4 and 93 years old). Male patients constituted $79.8 \%$ of the study population. Head trauma (43.4\%) was the most common etiology and the median time from emergency department admission to surgical intervention was 2 hours. Among the patient population, $74(74.7 \%)$ had an additional pathology. The most common additional pathologies were epidural hematoma and traumatic subarachnoid hemorrhage (SAH) (Table I).

The mean thickness of hematoma was $16.6 \pm 7.5 \mathrm{~mm}$. It was noted that the thickness of the ASDH was inversely correlated with the GCS score $(p<0.05)$. There was no statistically significant relationship between the mean ASDH thickness and trauma mechanism, presence of additional pathology, sex, age, and time interval between emergency department admission and operative procedure $(p>0.05)$.

Median GCS score was 12 and it was inversely proportional to the thickness of the hematoma $(p<0.05)$. The rate of an additional pathology was significantly high in patients with a low GCS score $(p<0.05)$. No significant relationship was found between GCS score and age, sex, and trauma mechanism $(p>0.05)$.

Marked improvement in GCS scores was noted in 54 patients on follow-up but the GCS score remained unchanged in 15 patients $(p<0.05)$. The mortality rate had no significant correlation with sex $(p>0.05)$. The mortality rate of the patients who experienced an out-of-vehicle traffic accident was high while the patients with isolated head trauma had a low mortality rate $(p<0.05)$. The patients with additional pathologies had an increased mortality $(p<0.05)$. The patients who died were old, presented earlier, and had a thick hematoma and low GCS scores $(p<0.05)$ (Tables II, III).

\section{DISCUSSION}

ASDH develops in approximately one third of brain injuries due to severe head trauma $(11,14)$. Although the mortality rate of ASDH was reported to be around $60 \%$ until the 1990 s, the rate was reduced to the level of $20 \%$ around 2000 and as low as $14 \%$ within the last decade (16). On the other hand, the functional recovery rate ranges between $19 \%$ and $45 \%$ in traumatic ASDH $(1,20)$. Although the indications for operation have not been clearly established in traumatic ASDH, craniotomy and decompressive craniectomy were performed for therapeutic purposes to induce brain relaxation (11). In the present study, all patients were operated as soon as possible after admission. Hematoma evacuation was accomplished with craniotomy or decompressive craniectomy, depending on factors such as clinical condition, hematoma size, and parenchymal edema of the patient. In patients with a lower GCS

Table I: Distribution of Patients according to Age, Sex and Trauma Mechanism

\begin{tabular}{llrr}
\hline \multirow{3}{*}{ Sex } & & $\mathbf{n}$ & \multicolumn{1}{c}{$\%$} \\
\hline \multirow{4}{*}{$\begin{array}{l}\text { Trauma } \\
\text { mechanism }\end{array}$} & Male & 79 & 79.8 \\
\cline { 2 - 4 } & Female & 20 & 20.2 \\
\cline { 2 - 4 } & Isolated head trauma & 43 & 43.4 \\
\cline { 2 - 4 } & Vehicle accident & 30 & 30.4 \\
\cline { 2 - 4 } & Falls & 24 & 24.2 \\
\hline \multirow{4}{*}{$\begin{array}{l}\text { Additional } \\
\text { pathologiers }\end{array}$} & Ethers & 2 & 2.0 \\
\cline { 2 - 4 } & SAH & 34.3 \\
\cline { 2 - 4 } & Depression fracture & 26 & 26.3 \\
\cline { 2 - 4 } & ICH & 7 & 7.1 \\
\cline { 2 - 4 } & Cerebral contusion & 7 & 7.1 \\
\cline { 2 - 4 } & Parenchymal Hematoma & 6 & 6.1 \\
\cline { 2 - 4 } & Fracture & 2 & 2.0 \\
\hline
\end{tabular}

SAH: Subarachnoid hemorrhage, ICH: Intracerebral hematoma. 
Table II: Comparison of Sex, Trauma Mechanism and Additional Pathologies with Mortality

\begin{tabular}{|c|c|c|c|c|}
\hline & & \multicolumn{2}{|c|}{ Mortality } & \multirow{2}{*}{$p^{*}$ value } \\
\hline & & Exitus $\mathrm{n}=30(\%)$ & Alive $\mathrm{n}=69(\%)$ & \\
\hline \multirow{2}{*}{ Sex } & Male & $23(29.1)$ & 56 (70.9) & \\
\hline & Female & $7(35.0)$ & $13(65.0)$ & 0.609 \\
\hline \multirow{4}{*}{ Trauma mechanism } & Isolated head trauma & $6(20.0)$ & $37(53.6)$ & \multirow{4}{*}{0.008} \\
\hline & Vehicle accident & $16(53.3)$ & $14(20.3)$ & \\
\hline & Falls & $7(23.3)$ & $17(24.6)$ & \\
\hline & Others & $1(3.3)$ & $1(1.5)$ & \\
\hline \multirow{2}{*}{ Additional pathologies } & Yes & $3(10.0)$ & $22(31.9)$ & \multirow{2}{*}{0.021} \\
\hline & No & $27(90.0)$ & $47(68.1)$ & \\
\hline
\end{tabular}

${ }^{*}$ Chi Square test.

Table III: Comparison of Age, ASDH Size and Admission Time with Mortality

\begin{tabular}{|c|c|c|c|c|c|c|}
\hline & Mortality & $\mathbf{n}$ & Mean/Median & Min/Max & $t / z$ & $\mathbf{p}$ \\
\hline \multirow{2}{*}{ Age (years) } & Exitus & 30 & $58.1 \pm 21.7$ & $4 / 94$ & \multirow{2}{*}{3.696} & \multirow[b]{2}{*}{$0.000^{\star}$} \\
\hline & Alive & 69 & $41.9 \pm 19.3$ & $6 / 85$ & & \\
\hline \multirow{2}{*}{ Size (mm) } & Exitus & 30 & $21.2 \pm 9.0$ & $10 / 45$ & \multirow[b]{2}{*}{4.316} & \multirow[b]{2}{*}{$0.000^{\star}$} \\
\hline & Alive & 69 & $14.7 \pm 5.8$ & $8 / 25$ & & \\
\hline \multirow{2}{*}{ GCS score } & Exitus & 30 & 6 (range:11) & $3 / 12$ & \multirow[b]{2}{*}{-6.326} & \multirow{2}{*}{0.000} \\
\hline & Alive & 69 & 13 (range:2) & $5 / 15$ & & \\
\hline \multirow{2}{*}{ Admission time } & Exitus & 30 & 1 (range:11) & $1 / 2$ & \multirow[b]{2}{*}{-2.476} & \multirow[b]{2}{*}{0.013} \\
\hline & Alive & 69 & 2 (range:359) & $1 / 3$ & & \\
\hline
\end{tabular}

Student-t test.

score and severe edema as an additional pathology, decompressive craniectomy was the preferred treatment modality. The aim of craniectomy was to provide sufficient space for brain relaxation and to prevent herniation.

Studies from United States and Europe demonstrated that traumatic ASDH has an important role on the mortality under the age of 45 (6). Ryan et al. reported that $63 \%$ of traumatic ASDH patients were male and the mean age of the study population was 58 years (16). Yanagawa et al. reported that $67 \%$ of the patients of traumatic ASDHs were male and the mean age was 43 years (23). Li et al. reported a male percentage of $60 \%$ with a mean age of 51 years (11). Shen et al. reported that the majority of the affected patients were male and the patient population had a mean age of 36 years (17). Okten et al. studied a traumatic ASDH patient population with a mean age of 39 years and they observed that $76 \%$ of the patients were male (15). In our study, $79.8 \%$ of our patients were male and their mean age was 47 years. Thus, our population's mean age and male percentage were similar to series reported in the literature. We believe that an increased percentage of driving and occupational accidents, as well as a higher rate of assault incidents among adults, are the factors that shaped the mean age of our population. Men are exposed more to trauma since they spend more time out of their house and are more commonly involved in risky jobs such as working in high places (building sites, high-voltage transmission lines) and driving vehicles compared to women.

Ryan et al. reported that the most common cause of traumatic ASDH was falls from heights, followed by motor vehicle accidents (16). Leitgeb et al. similarly reported that falls and traffic accidents were the most common causes of traumatic ASDH (10). Yanagawa et al. observed that ASDH most commonly resulted from traffic accidents (23). It was also reported that falls were the most common cause of $\mathrm{ASDH}$, followed by traffic accidents (19). In another study, traffic accidents were followed by falls and considered as the two most common causes of ASDH (22). In a study from Turkey, Kaptanoglu et al. found similar results for the most common causes of ASDH (7). In contrast to former studies, we found that isolated head trauma was the most common etiology of ASDH. The basic 
reasons of this discrepancy may be the geographical location of the center included in the study as it is close to suburban areas.

It is well known that parenchymal lesions and edema developing inside the brain are the most important factors determining the clinical course of ASDH (11). Shen et al. reported that cranium fractures and brain edema were the main additional pathologies in their study population (17). Leitgeb et al. reported that $\mathrm{SAH}$ and contusion ranked top among additional pathologies also emphasized by Son et al. $(10,19)$. In our study, the contusion rate of our population was lower and the rates of epidural hematoma and SAH were found to be higher in contrast to the literature. In the former studies, the mechanisms of trauma were traffic accidents and falls from heights, which potentially caused greater damage. Isolated head traumas concentrating the energy of impact onto a single point ranked at the first place as the mechanism of trauma in our study, which may explain the difference between the data in the literature and our findings.

It was reported that midline shift due to ASDH is related to GCS score and mortality (4). Chen et al. reported that the mean diameter of ASDH bleeding was $11 \mathrm{~mm}$ and the measurement is parallel to the degree of midline shift (3). In a study performed on 21 patients by Yanagawa et al., a mean GCS score of 4.8 was noted and the size of ASDH was $13.1 \mathrm{~mm}$ (23). Son et al. reported a mean hematoma size of $5.8 \mathrm{~mm}$ and the size was proportional to the amount of shift. They also found that the hematoma size was smaller in patients who later deteriorated or whose hematoma was spontaneously resorbed (19). Solaroglu et al. determined that the size of bleeding and the amount of shift was greater in patients who died compared to those who did not (18). We believe that the increased amount of bleeding is a direct parameter of injured parenchyma but it also results in secondary losses by inducing more edema due to an increase in the space that it occupies. Thus, we advocate that the size of $\mathrm{ASDH}$ is proportional to the clinical course.

GCS is a practical classification method that has three components (verbal, motor, eye), each of which signifies separate areas of brain. Therefore, it has been reported that it is the most important factor that directly reflects brain damage, reflects clinical status, and provides information on survival during follow-up $(10,12)$. Son et al. reported a mean admission GCS score of 13.2 (19). It was reported in another study that most of the patients had a GCS score greater than 13, followed by patients with a GCS score lower than 6 , and interventions were most commonly performed on patients with a low GCS score (16). Nevertheless most of the patients with ASDH had a GCS lower than 8 in general $(7,11)$. Moreover, patients with additional pathologies had a lower GCS (10). Ryan et al found that GCS increased after follow-up and surgery (16). It was also noted that the patients who survived generally improved later (9). Interestingly, Son et al. followed their patients without intervention and observed that $77 \%$ of the hematomas were resorbed spontaneously and the GCS score improved there after (19). We observed an improvement in the GCS score of our patients in time at the present study. The main reason of this observation is possibly an improvement in the consciousness of patients followed by a higher GCS score as a result of surgical decompression, spontaneous hematoma resolution and regression of edema.

The mortality rate of traumatic ASDH is about $40 \%$ to $60 \%$ $(10,13)$. Many factors including age have been reported to influence mortality in traumatic and non-traumatic ASDH patients $(4,21)$. Busl and Prabhakaran found a mortality rate of $11.8 \%$ in patients with ASDH and reported that the rate was lower in traumatic ASDH patients (2). Ryan et al. reported a mortality rate of $14 \%$ (16). In the study of Leitgeb et al., the mortality rate was found to be $47 \%$ and additional trauma and mortality were found to be increased as the GCS score was lowered (10). Previous studies have reported that the GCS score was strongly correlated to mortality $(8,9)$. Shen et al. reported that the mortality rate was higher in patients with a lower GCS score (17). Leitgeb et al. demonstrated a higher mortality rate in patients with additional traumatic lesions (10). Kaptanoglu et al. reported lower mortality in patients operated earlier (7). We found higher mortality in out-of-vehicle traffic accidents possibly due to the severity of the trauma. As expected, the mortality rate becomes higher in patients with additional traumatic lesions depending on the increased amount of affected brain tissue. In our study, the mortality increased with the increasing age of the patients. This was possibly because of a reduced physiological reserve of the aging population, reduced brain plasticity, and increased rates of comorbidities in that patient population. An increased amount of bleeding will cause more brain tissue to become affected and the GCS score to be lowered. Thus, it was found in the present study that the mortality rate is higher in traumatic ASDH patients with a large hematoma and a lower GCS.

\section{CONCLUSION}

Traumatic ASDH is a fatal condition despite all developments in neurosurgical interventions. GCS score and hematoma size are important parameters that correlate with the mortality rate. Other factors affecting mortality are age, presence of additional trauma, and time delay from admission to intervention.

\section{REFERENCES}

1. Bullock M, Chesnut R, Ghajar J, Gordon D, Hartl R, Newell D: Surgical management of traumatic brain injury. Neurosurgery 58-61, 2006

2. BusI KM, Prabhakaran S: Predictors of mortality in non traumatic subdural hematoma. J Neurosurg 119(5):12961301, 2013

3. Chen SH, Chen Y, Fang WK, Huang DW, Huang KC, Tseng SH: Comparison of craniotomy and decompressive craniectomy in severely head-injured patients with acute subdural hematoma. J Trauma 71(6):1632-1636, 2011

4. El-Fiki M: Acute traumatic subdural hematoma outcome in patients older than 65 years. World Neurosurg 78(3-4):228230, 2012 
5. Godlewski B, Pawelczyk A, Pawelczyk T, Ceranowicz K, Wojdyn M, Radek M: Retrospective analysis of operative treatment of a series of 100 patients with subdural hematoma. Neurol Med Chir (Tokyo) 53(1):26-33, 2013

6. Hyder AA, Wunderlich CA, Puvanachandra P, Gururaj G, Kobusingye OC: The impact of traumatic brain injuries: $A$ global perspective. Neuro Rehabilitation 22:341-353, 2007

7. Kaptanoglu E, Solaroglu I, Ucar MD, Okutan MO, Beskonakli E, Taskin Y: Acute subdural hematomas. Analysis of 73 cases. Ulus Travma Acil Cerrahi Derg 7(4):246-249, 2001

8. Kilincaslan M, Kaptan $\mathrm{H}$, Ilhan M, Kasimcan O, Cakiroglu K, Kilic C: Prognostic factors and their effects on mortality in traumatic acute subdural haematoma. Sinir Sistemi Cerrahisi Dergisi 1(4):214-219, 2008

9. Koc RK, Akdemir H, Oktem IS, Meral M, Menku A: Acute subdural hematoma: Outcome and outcome prediction. Neurosurg Rev 20:239-244, 1997

10. Leitgeb J, Mauritz W, Brazinova A, Janciak I, Majdan M, Wilbacher I: Outcome after severe brain trauma due to acute subdural hematoma. J Neurosurg 117(2):324-333, 2012

11. Li LM, Kolias AG, Guilfoyle MR, Timofeev I, Corteen EA, Pickard JD, Menon DK, Kirkpatrick PJ, Hutchinson PJ: Outcome following evacuation of acute subdural haematomas: $A$ comparison of craniotomy with decompressive craniectomy. ActaNeurochir (Wien) 154(9):1555-1561, 2012

12. Marmarou A, Lu J, Butcher I, McHugh GS, Murray GD, Steyerberg EW: Prognostic value of the Glasgow Coma Scale and pupil reactivity in traumatic brain injury assessed prehospital and on enrollment: An IMPACT analysis. J Neurotrauma 24:270-280, 2007

13. Meyer S, Gibb T, Jurkovich GJ: Evaluation and significance of the papillary light reflex in trauma patients. Ann Emerg Med 22:1052-1057, 1993

14. Murray GD, Teasdale GM, Braakman R, Cohadon F, Dearden $\mathrm{M}$, lannotti $\mathrm{F}$ : The European Brain Injury Consortium survey of head injuries. Acta Neurochir (Wien) 141:223-236, 1999
15. Okten Al, Gezercan Y, Ergun R: Traumatic subarachnoid hemorrhage: A prospective study of 58 cases. Ulus Travma Acil Cerrahi Derg 12(2):107-114, 2006

16. Ryan CG, Thompson RE, Temkin NR, Crane PK, Ellenbogen RG, Elmore JG: Acute traumatic subdural hematoma: Current mortality and functional outcomes in adult patients at a Level I trauma center. J Trauma Acute Care Surg 73(5):1348-1354, 2012

17. Shen J, Pan JW, Fan ZX, Zhou YQ, Chen Z, Zhan RY: Surgery for contralateral acute epidural hematoma following acute subdural hematoma evacuation: Five new cases and a short literature review. Acta Neurochir (Wien) 155(2):335-341, 2013

18. Solaroglu I, Kaptanoglu E, Okutan O, Beskonakli E, Taskin Y: Prognostic value of initial computed tomography findings in patients with traumatic acute subdural hematoma. Turk Neurosurg 12:89-94, 2002

19. Son S, Yoo CJ, Lee SG, Kim EY, Park CW, Kim WK: Natural course of initially non-operated cases of acute subdural hematoma: The risk factors of hematoma progression. J Korean Neurosurg Soc 54(3):211-219, 2013

20. Tallon JM, Ackroyd-Stolarz S, Karim SA, Clarke DB: The epidemiology of surgically treated acute subdural and epidural hematomas in patients with head injuries: A population-based study. Can J Surg 51:339-345, 2008

21. Valadka AB, Sprunt JM: Craniotomy for acute subdural hematoma in the elderly: Not as bad as you thought. World Neurosurg 78(3-4):231-232, 2012

22. Wilberger JE Jr, Harris M, Diamond DL: Acute subdural hematoma: Morbidity, mortality, and operative timing. J Neurosurg 74(2):212-218, 1991

23. Yanagawa $Y$, Sakamoto T: Results of single burr hole drainage for acute subdural hematoma with non-reactive pupil. Turk Neurosurg 22(2):196-199, 2012

24. Yildirim H, Ozturk T, Esen M: Akut subdural hematomun spontan rezolüsyon ve redüstirbüsyonu: $B T$ ve $M R$ bulguları. Fırat Tıp Dergisi 16(3):137-140, 2011 (In Turkish) 